\title{
A DIRECT DETERMINATION OF AN UPPER LIMIT FOR THE ELEGTRICAL CHARGE ON DISLOCATIONS IN ICE*
}

\author{
By D. M. Joncich \\ (Department of Physics and Materials Research Laboratory, University of Illinois at \\ Urbana-Champaign, Urbana, Illinois 6ı8о, U.S.A.)
}

J. Holder,

(Department of Geology and Materials Research Laboratory, University of Illinois at Urbana-Champaign, Urbana, Illinois 6ı1801, U.S.A.)

and A. V. Granato

(Department of Physics and Materials Research Laboratory, University of Illinois at Urbana-Champaign, Urbana, Illinois 6ı 801, U.S.A.)

\begin{abstract}
A direct determination of the upper limit for the electric charge density along dislocations in ice has been carried out by measuring the simultaneous effects of an electric field and a mechanical stress on the movement of a low-angle tilt boundary in an ice single crystal. The determination is independent of the geometry of the dislocations or the distribution of the charge along them. No measurable effects of the electric field on boundary motion were found, requiring that the charge density be less than one unit of charge for every 300 atomic lengths of dislocation. This estimate is less than large previous estimates, but is consistent with smaller proposed values.

RÉsumé. Une détermination directe de la limite supérieure de la charge électrique des dislocations dans la glace. Pour déterminer directement la limite supérieure de la charge électrique le long des dislocations de la glace, on a mesuré les effets simultanés d'un champ électrique et d'une contrainte mécanique sur le mouvement d'une face de faible inclinaison dans un monocristal de glace. La mesure ne dépend pas de la géométrie des dislocations ni de la distribution des charges électriques le long d'elles. On n'a pas trouvé d'effet mesurable du champ électrique sur le mouvement de la face tant que la charge était inférieure à une unité pour 300 longueurs de dislocation. Cette estimation est inférieure aux fortes valeurs avancées antérieurement, mais corrobore des évaluations proposées plus faibles.

Zusammenfassung. Eine direkte Bestimmung der oberen Grenze für die elektrische Ladung an Versetzungen in Eis. Die obere Grenze für die elektrische Ladungsdichte entlang von Versetzungen in Eis wurde durch die gleichzeitige Messung der Wirkungen eines elektrischen Feldes und einer mechanischen Spannung auf die Bewegung einer schwach geneigten Grenzfläche in einem Eis-Einkristall direkt bestimmt. Die Bestimmung ist unabhängig von der Geometrie der Versetzungen oder von der Ladungsverteilung längs dieser Versetzungen. Es ergaben sich keine messbaren Effekte des elektrischen Feldes auf die Bewegung der Grenzfläche, sofern die Ladungsdichte geringer als eine Ladungseinheit für je 300 atomare Versetzungseinheiten war. Diese Schätzung liegt unter den höheren Werten, die früher vorausgesetzt wurden, stimmt jedoch mit den Annahmen kleinerer Werte überein.
\end{abstract}

A number of previous studies have suggested that dislocations in ice are electrically charged (Brill and Camp, I957; Itagaki, I970, I978; Mae and Higashi, 1973; Noll, I973). Unfortunately, there has been no definite experimental determination of this charge. The previous studies were indirect measurements of the dislocation charge, and the resulting values estimated for the charge density range over several orders of magnitude. Brill and Camp (1957), Noll (1973), and Mae and Higashi (1973) reported small but observable changes in the low-frequency (space-charge) region of the dielectric constant for plasticallydeformed samples. They associated this phenomenon with a dislocation charge on the order of one unit or less of charge per $10^{6}$ atomic lengths of dislocation. On the other hand, Itagaki (unpublished) reported large changes in the dielectric constants of samples with deformation. He interprets his X-ray topographic observations (Itagaki, 1970) of dislocations in samples acted upon by an applied a.c. electric field $(60 \mathrm{~Hz})$ in terms of a charge density of one unit of charge per $\mathrm{IO}^{-} \mathrm{IO}^{2}$ atomic dislocation lengths.

* This research was supported in part by the National Science Foundation under contract DMR-76-01058 and DMR-77-10556. 
The purpose of the present note is to report a direct determination of an upper limit for the charge density of edge dislocations in ice. The determination is based on the observation of the motion of a low-angle tilt boundary, made up of an array of parallel, edge dislocations, under the influence of both an applied mechanical stress $\sigma$ and an electric field $E$. For every dislocation segment in the boundary the mechanical force per unit length is $b \sigma$, where $b$ is the Burgers' vector, and the electrical force per unit length is $\lambda E$, where $\lambda$ is the charge per unit length. For the particular values of $\sigma$ and $E$ for which the observed displacements (or velocity) of the boundary are equal, the magnitude of the charge per unit length is given entirely in terms of those values

$$
\lambda=b \sigma / E .
$$

This determination is independent of the nature of the dislocation geometry and of any assumptions about the distribution of the charge along the dislocation.

The single-crystal specimens used in the study were grown by a zone-refining process. The apparatus is similar to that described by Ramseier (unpublished), and is described elsewhere (Joncich, unpublished, p. 52-53). Individual samples measuring $2 \times 1 \times 1 \mathrm{~cm}^{3}$ were cut from the $7 \mathrm{~cm}$ diameter ingot with a hot-wire saw, and were oriented (to within about $2^{\circ}$ ) using crossed polarizers. The $c$-axis lay parallel to one of the $\mathrm{I} \mathrm{cm}$ directions.

A low-angle tilt boundary of approximately $3^{\circ}$ was introduced into the specimen by applying a $2 \mathrm{~kg}$ mass near to the center of the specimen, in a three-point bending jig, for about $24 \mathrm{~h}$. The specimen temperature during all the tests was approximately $-15^{\circ} \mathrm{C}$.

The sample was then mounted as shown in Figure $\mathrm{I}$. The two metal plates were frozen to the two $\mathrm{I} \times \mathrm{I} \mathrm{cm}^{2}$ faces of the sample. A mechanical stress was applied by applying a mass $M$ on the right-hand metal plate, and a electrical field was applied between the two electrodes. The left-hand brass plate was rigidly fixed, while the right-hand copper plate was free to move. The displacement of the wall could be monitored optically for rough measurements ( $>$ o.o I mm), or alternatively the vertical displacement of the right-hand electrode could be measured. For a given displacement $d$ of the wall, the vertical displacement of the right-hand plate is $x d \tan \theta$, where $\theta$ is the tilt-angle boundary. The vertical displacements were measured with a Statham displacement gauge (model UC 3 ) used with a PAR model JB-5 lock-in amplifier. The output of the amplifier was displayed on a strip-chart recorder, and the system was calibrated over a range of $0.2 \mathrm{~mm}$ using a micrometer screw gauge. The sample

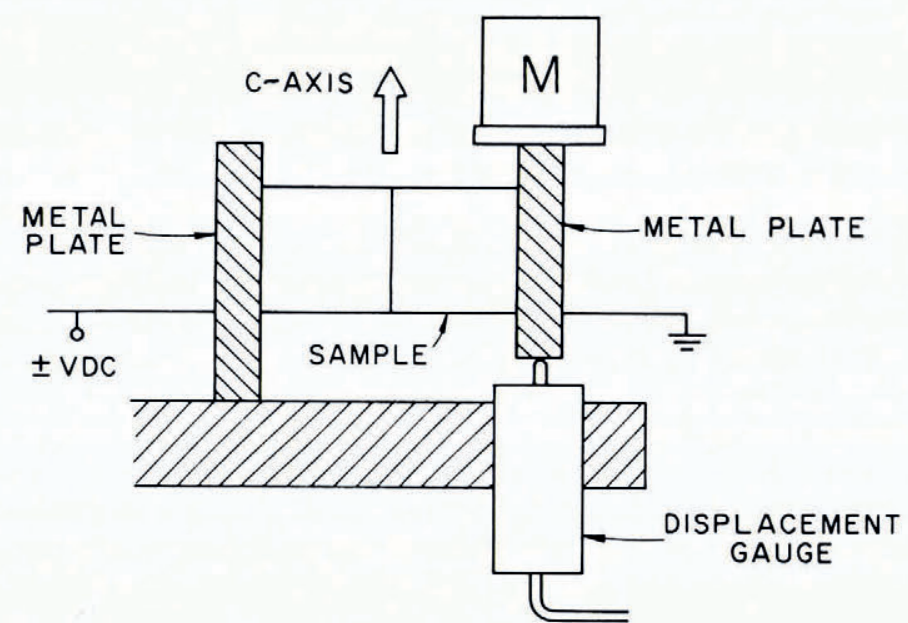

Fig. I. Sample configuration for measurements of the effects of electric and mechanical forces on a low-angle tilt boundary. The left-hand plate is brass and the right-hand plate is copper. 
and jig were placed within a chamber inside which the temperature was maintained at $-15{ }^{\circ} \mathrm{C}$ to within $\mathrm{I}$ deg during the measurements.

For the measurements the tilt boundary was first moved with a mechanical stress. Then, with the mechanical stress still applied, an electric potential difference of $3250 \mathrm{~V}$ was applied between the two metal plates.

This electric field could not be maintained indefinitely, but decayed with a time constant of about five minutes. This decay results from the build-up of space charge at the non-ohmic contacts with the electrodes; this value of the time constant is in agreement with previous measurements (Engelhardt and others, 1969). Hence, for the present measurements, the electric potential was switched between o and $\pm 3250 \mathrm{~V}$ with a period of about $30 \mathrm{~s}$. The resulting electric field in the sample was then either o or at least $\mathrm{I} 500 \mathrm{~V} / \mathrm{cm}$.

The results for one of the several measurements are shown in Figure 2. The stress of 0.2 bar was applied at time $t=0$. After an initial transient period of about $30 \mathrm{~s}$ the wall velocity is constant, at $0.24 \mathrm{~mm} / \mathrm{h}$, in agreement with the observations of Higashi and Sakai ( 196 I $)$.

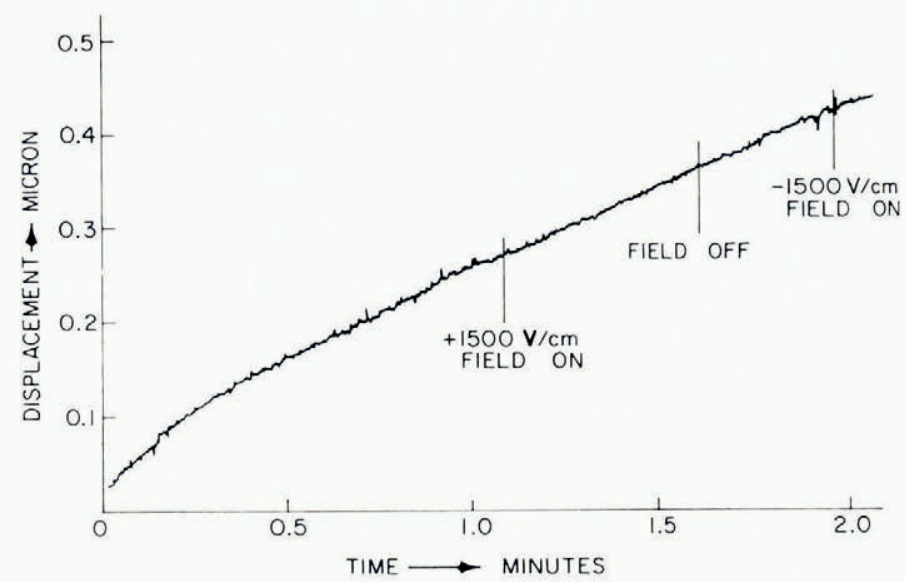

Fig. 2. Measured vertical displacement of the end of the sample as a function of time, with a constant mechanical stress of o.2 bar and the indicated periodic electric fields.

The electric potential was switched between $\mathrm{o}$ and $\pm 3250 \mathrm{~V}$ at the times indicated. In no case was there any observable change in velocity, so only an upper limit for the charge density can be estimated from the results. As noted, the field inside the sample should be at least I $500 \mathrm{~V} / \mathrm{cm}$ during the brief cycles (local field corrections would increase this quantity), and a conservative estimate for the resolution of the velocity is $\pm 2 \%$. From Equation (I), the charge density of the edge dislocations must be less than

$$
0.02(b \sigma / E)=7 \times 10^{-4} e / \AA .
$$

This corresponds to only about one unit of charge for every 300 atomic lengths of dislocation. The dislocations in the tilt boundary are of the same sign so that this charge density limit should apply directly to the edge dislocations in the boundary.

The edge dislocation charge density is much less than the upper limit proposed by Itagaki (1970), but is consistent with the values estimated by Higashi and Sakai (196I) for screw dislocations. In fact, the edge dislocations could be expected to have the greatest charge density because they have the largest number of dangling bonds per unit length (Osipiyan and Smirnova, 1968). 
In summary, the present results indicate that dislocations in ice are not heavily charged electrically, so that any charge present is probably associated with a small number of ionic defects distributed along the dislocation (Mae and Higashi, 1973) rather than a large intrinsic charge associated with each dangling bond at the dislocation core. Further, the results suggest that the large dielectric relaxation peak in ice (Schiller, I958) is not the result of charged dislocation motion.

\section{Acknowledgement}

The authors are indebted to Dr K. Itagaki of the U.S. Army Cold Regions Research and Engineering Laboratory for his advice concerning the apparatus for the growth and preparation of the ice samples.

MS. received 9 November 1977 and in revised form ${ }_{15}$ February 1978

\section{REFERENGES}

Brill, R., and Camp, P. 1957. Influence of pressure on the dielectric properties of ice. Nature, Vol. 179, No. 456o, p. 623-24.

Engelhardt, H., and others. I969. Protonic conduction of ice. Part II : low temperature region, [by] H. Engelhardt, B. Bullemer, N. Riehl. (In Riehl, N., and others, ed. Physics of ice: proceedings of the international symposium on physics of ice, Munich, Germany, September 9-14, 1968. Edited by N. Riehl, B. Bullemer, H. Engelhardt. New York, Plenum Press, p. 430-42.)

Higashi, A., and Sakai, N. r961. Movement of small angle boundary of ice. Journal of the Faculty of Science, Hokkaido University, Ser. 2, Vol. 5, No. 5, p. $221-37$.

Itagaki, K. I970. X-ray topographic study of vibrating dislocations in ice under an AC electric field. Advances in $X$-Ray Analysis, Vol. 13 , p. 526-38.

Itagaki, K. 1978. Dielectric properties of dislocation-free ice. Fournal of Glaciology, Vol. 21, No. 85, p. $207-17$.

Joncich, D. M. Unpublished. The plastic behavior of predeformed ice crystals. [Ph.D. thesis, University of Illinois, I976.]

Mae, S., and Higashi, A. 1973. Effects of plastic deformation on the dielectric properies of ice. Crystal Lattice Defects, Vol. 4, No. 4, p. $295^{-308 .}$

Noll, G. 1973. Influence of plastic deformation on the electrical properties of ice Ih single crystals. (In Whalley, E., and others, ed. Physics and chemistry of ice: papers presented at the Symposium on the Physics and Chemistry of Ice, held in Ottawa, Canada, I4-18 August 1972. Edited by E. Whalley, S. F. Jones, L. W. Gold. Ottawa, Royal Society of Canada, p. 350-55.)

Osipiyan, Yu. A., and Smirnova, I. S. 1968. Perfect dislocations in the wurtzite lattice. Physica Status Solidi, Vol. 30, No. I, p. 19-29.

Ramseier, R. O. Unpublished. Growth and mechanical properties of river and lake ice. [Ph.D. thesis, Université Laval, Quebec, r971.]

Schiller, P. 1958. Die mechanische Relaxation in reinen Eiseinkristallen. Zeitschrift für Physik, Bd. 153, Ht. I, p. $1-15$. 